\title{
Effects of carboplatin combined with paclitaxel-based intraperitoneal hyperthermic perfusion chemotherapy on serum levels of HE4 and DJ-1 in patients with advanced recurrent ovarian cancer
}

\author{
Xianhui Su${ }^{1}$, Xuewen Sun ${ }^{2}$, \\ Yanhui Kang ${ }^{3}$, Yuna Dai ${ }^{4}$
}

\begin{abstract}
Objective: To analyze the effects of carboplatin combined with paclitaxel-based intraperitoneal hyperthermic perfusion chemotherapy (IPCH) on serum levels of human epididymis protein 4 (HE4) and mitogen-dependent oncogene-1 (DJ-1) in patients with advanced recurrent ovarian cancer (OC).

Methods: From July 2019 to July 2020, patients with advanced recurrent OC $(n=92)$ treated in Affiliated Hospital of Hebei Engineering University were selected as study subjects. According to the random number table method, patients were divided into control group and observation group. Patients in the control group were treated with carboplatin combined with paclitaxel-based intravenous chemotherapy, and patients in the observation group were treated with carboplatin combined with paclitaxel-based IPCH. The therapeutic effects, serum levels of HE4, DJ-1 and human kallikrein 10 (HK-10), peripheral blood immune indexes and adverse reactions of patients were compared between the two groups.

Results: The response rate of the observation group was significantly higher than that of the control group $(p<0.05)$; after treatment, the indexes of HE4, DJ-1 and HK-10 in the two groups were significantly decreased, while the indexes of $\mathrm{CD}^{+} \mathrm{CD}^{+}, \mathrm{CD}^{+} \mathrm{CD}^{+} 6^{+}$and $\mathrm{CD3}^{+} \mathrm{CD} 4^{+} / \mathrm{CD} 3^{+} \mathrm{CD} 8^{+}$were significantly increased; moreover, significantly lower indexes of HE4, DJ-1 and HK-10 and significantly higher indexes of CD3 ${ }^{+} \mathrm{CD}^{+}$, $\mathrm{CD3}^{+} \mathrm{CD}^{+} 6^{+}$and $\mathrm{CD}^{+}{ }^{+} \mathrm{CD} 4^{+} / \mathrm{CD}^{+} \mathrm{CD}^{+}$were found in the observation group when compared with the control group $(p<0.05)$. The severity of myelosuppression, nausea and vomiting in the observation group was significantly lower than that in the control group, and the total tumor metastasis rate in the observation group was significantly lower than that in the control group $(p<0.05)$.

Conclusions: Carboplatin combined with paclitaxel IPCH had obvious inhibitory effects on HE4, DJ-1 and other serum tumor markers in patients with advanced recurrent OC, with a more prominent clinical effect, and could further significantly reduce the risk of adverse reactions and metastasis.
\end{abstract}

KEYWORDS: Chemotherapy; Ovarian cancer cells; Tumor markers.

doi: https://doi.org/10.12669/pjms.38.4.4736

How to cite this:

Su X, Sun X, Kang Y, Dai Y. Effects of carboplatin combined with paclitaxel-based intraperitoneal hyperthermic perfusion chemotherapy on serum levels of HE4 and DJ-1 in patients with advanced recurrent ovarian cancer. Pak J Med Sci. 2022;38(4):872-877. doi: https://doi.org/10.12669/pjms.38.4.4736

This is an Open Access article distributed under the terms of the Creative Commons Attribution License (http://creativecommons.org/licenses/by/3.0), which permits unrestricted use, distribution, and reproduction in any medium, provided the original work is properly cited.

Note: Xianhui Su and Xuewen Sun are both considered as co-first authors.

Correspondence:

Yuna Dai,

Breast Surgery,

Affiliated Hospital of Hebei Engineering University,

Handan 056029, Hebei, China.

E-mail: sxw1262@126.com

* Received for Publication:

* Revision Received:

* Revision Accepted: *
May 19, 2021

December 4, 2021

December 29, 2021

\section{INTRODUCTION}

Ovarian cancer (OC), a malignant tumor growing in ovarian tissues, was more common in gynecologic malignancies. According to the clinical treatment experience ${ }^{1,2}$, it has been found that the morbidity of OC was second only to cervical cancer and endometrial cancer. However, the mortality of OC was the highest among gynecologic malignancies, resulting in serious adverse effects on women's 
physical health and safety. In recent years, surgery has been believed as the main clinical plan for the treatment of OC, supplemented by chemotherapy. Surgical treatment could remove the lesion tissues to the maximum extent and reduce the burden for subsequent chemotherapy. ${ }^{3,4}$ In addition, targeted therapy, immunotherapy, traditional Chinese medicine treatment and other methods also had certain improvement effects in the recovery process of OC patients, but with limited research data, thus continuous analysis and exploration were still necessary. ${ }^{5,6}$ Among the chemotherapy drugs for OC, carboplatin, a broad-spectrum anti-tumor drug, had almost no cross resistance, high drug activity and low risk of gastrointestinal adverse reactions and nephrotoxicity, with certain clinical application value, but targeted nursing should be performed against myelosuppression and other side effects. Paclitaxel was extracted from a natural plant--Taxus chinensis, with the main anti-cancer component being diterpenoid alkaloids, and paclitaxe played a key role in the treatment of OC patients. ${ }^{7,8}$ Generally, conventional chemotherapy was administered through the intravenous route. A relevant study has proposed that, for patients with advanced recurrent OC, intraperitoneal hyperthermic perfusion chemotherapy (IPCH) could further improve the treatment efficiency and the quality of life of patients. ${ }^{9}$ In this study, ninety-two patients with advanced recurrent OC were selected to be performed with intravenous chemotherapy and IPCH by grouping, the recovery of different patients was analyzed, and the report was submitted as follows:

\section{METHODS}

Patients with advanced recurrent OC $(\mathrm{n}=92)$ treated in Affiliated Hospital of Hebei Engineering University from July 2019 to July 2020 were selected as the study subjects.

Ethical approval: The study was approved by the Institutional Ethics Committee of Affiliated Hospital of Hebei Engineering University, and written informed consent was obtained from all participants.

\section{Inclusion criteria:}

- Patients with recurrent epithelial OC (clinical stage, III-IV) who were confirmed according to the relevant diagnostic criteria ${ }^{10}$ and pathological and cytological examination results;

- Patients without other surgical operations performed in the past six months;

- Patients who agreed to voluntarily participate in this study;
- Patients with perfect clinical records.

- Exclusion criteria:

- Patients diagnosed with neuropsychiatric disease or cognitive impairment;

- Patients diagnosed with severe organic disease or physical disability;

- Patients in pregnancy or lactation;

- Patients combined with other malignant tumors. According to the random number table method, the enrolled patients were divided into two groups: the control group $(n=46)$ and the observation group $(n=46)$. Patients in the control group were $30-60$ years old, with an average age of $44.59 \pm 1.33$ years old; as for tumor typing, there were 27 cases of serous adenocarcinoma, 10 cases of endometrioid carcinoma and nine cases of mucinous adenocarcinoma; regarding clinical staging, there were 18 cases of stage IIIa, 16 cases of stage IIIb, 12 cases of stage IV. Patients in the observation group was 32-64 years old, with an average age of $45.06 \pm 5.28$ years old; as for tumor typing, there were 26 cases of serous adenocarcinoma, 11 cases of endometrioid carcinoma and 9 cases of mucinous adenocarcinoma; regarding clinical staging, there were 16 cases of stage IIIa, 17 cases of stage IIIb and 13 cases of stage IV. There was no significant difference in general information between the two groups $(p>0.05)$.

Methods: Patients in both groups received conventional treatment, such as diuretic therapy, hydration treatment, prevention and treatment of vomiting, etc., and received antianaphylactic treatmentt, such as intramuscular injection of diphenhydramine (Shanghai zhaohui Pharmaceutical Co., Ltd., SFDA approval number: H31021087) one hour before chemotherapy. (1) Patients in the control group was treated with carboplatin combined with paclitaxelchemotherapy; drugs: Carboplatin Injection (Bristol-Myers Squibb S.R.L., SFDA approval number: H20171063, 150 $\mathrm{mg} /$ tube) and Paclitaxel Injection (Bristol-Myers Squibb S.R.L., HJ20171227, 30 mg/5ml); methods: intravenous drip of Paclitaxel Injection was carried out, with the specification being $175 \mathrm{mg} / \mathrm{m}^{2}, \mathrm{~d} 1$; intravenous drip of Carboplatin Injection was performed, with the specification being 5.6 AUC, $\mathrm{d} 1$; and treatment cycle: once per 28 days;

Patients in the observation group were treated with carboplatin combined with paclitaxel IPCH, catheterization was carried out in the abdominal cavity of patients (the catheterization site was in the central venous vessel), and drugs and normal saline $\left(1,500 \mathrm{ml}\right.$, about $\left.45^{\circ} \mathrm{C}\right)$ were infused through the catheter, the specifications of Paclitaxel Injection 
Study on patients with advanced recurrent ovarian cancer

Table-I: Comparison of treatment effects between patients in the observation group and the control group (n, \%).

\begin{tabular}{lcccccc}
\hline Group & Cases & $\begin{array}{c}\text { Complete } \\
\text { remission }\end{array}$ & $\begin{array}{c}\text { Partial } \\
\text { remission }\end{array}$ & $\begin{array}{c}\text { Disease } \\
\text { progression }\end{array}$ & $\begin{array}{c}\text { Disease } \\
\text { stabilization }\end{array}$ & $\begin{array}{c}\text { Response } \\
\text { rate }\end{array}$ \\
\hline Control group & 46 & 6 & 14 & 15 & 11 & $20(43.48)$ \\
Observation group & 46 & 8 & 22 & 9 & 8 & $30(65.22)$ \\
$\mathrm{X}^{2}$ & & & & & & 4.381 \\
$\mathrm{p}$ & & & & & & 0.036 \\
\hline
\end{tabular}

and Carboplatin Injection were $75 \mathrm{mg} / \mathrm{m}^{2}$ and 150 $\mathrm{mg} / \mathrm{m}^{2}$, respectively; duration of hyperthermic perfusion: 1 hour per time; frequency of position conversion: $20 \mathrm{~min} /$ time, 3-4 times in total (conducive to uniform drug distribution); and treatment cycle: once per seven days and then suspended for seven days after three consecutive sessions. The study cycle was 3 months.

Observation indexes: The treatment effects were compared between the two groups, and ImmuneModified Response Evaluation Criteria In Solid Tumors (imRECIST) ${ }^{11}$ was used as the evaluation tool. The specific contents were: complete remission (all the target lesions of patients were eliminated), partial remission (the maximum diameter reduction rate of the target lesions of patients was 20\%-30\% after treatment), disease progression (the maximum diameter growth rate of the target lesions of patients was $20 \%-30 \%$ after treatment), disease stabilization (the disease state of patients was between partial remission and disease progression), and the response rate $=$ (complete remission + partial remission) cases/total cases $\times 100 \%$.

The serum tumor markers, including human epididymal protein 4 (HE4), mitogen-dependent oncogene-1 (DJ-1), human kallikrein 10 (HK-10), were compared between the two groups before and after treatment; test methods: fasting venous blood $(5 \mathrm{ml})$ samples were collected, after conventional centrifugal separation, HE4, DJ-1 and HK-10 were determined by double-antibody sandwich enzymelinked immunosorbent assay (ELISA).

The peripheral blood immune indexes were compared between the two groups before and after treatment, including $\mathrm{CD}^{+} \mathrm{CD}^{+}, \mathrm{CD}^{+} \mathrm{CD}^{+} 6^{+}$and $\mathrm{CD}^{+} \mathrm{CD}^{+} / \mathrm{CD}^{+} \mathrm{CD}^{+}$; methods: fasting peripheral venous blood $(5 \mathrm{ml})$ samples were collected from patients, and $\mathrm{CD}^{+} \mathrm{CD}^{+}, \mathrm{CD}^{+} \mathrm{CD}_{5} 6^{+}, \mathrm{CD}^{+} \mathrm{CD}^{+} /$ $\mathrm{CD}^{+} \mathrm{CD}^{+}$and other indicators were measured by Attune NxT flow cytometry.

The adverse reactions were compared between the two groups after treatment, with the main observation objects being myelosuppression and nausea and vomiting symptoms, and the severity of adverse reactions was divided into 0-IV grade according to the RTOG/EORTC criteria ${ }^{12}$; and tumor metastasis status was compared between the two groups after treatment.

Statistical Analysis: SPSS21.0 software was selected to analyze the relevant data of the study. The enumeration data was expressed as rate (\%), $X^{2}$ test was performed, and ranked data was analyzed by rank-sum test; while the measurement data was expressed as mean \pm standard deviation $(\bar{X} \pm s)$, and $t$ test was performed. $\mathrm{P}<0.05$ was considered as statistically significant.

\section{RESULTS}

The response rate of the observation group was significantly higher than that of the control group

Table-II: Comparison of serum tumor markers between the two groups before and after treatment $(\bar{X} \pm s)$.

\begin{tabular}{|c|c|c|c|c|c|c|c|}
\hline \multirow{2}{*}{ Group } & \multirow{2}{*}{ Cases } & \multicolumn{2}{|c|}{ HE4 (pmol/L) } & \multicolumn{2}{|c|}{$D J-1(\mu g / L)$} & \multicolumn{2}{|c|}{ HK-10 ( $\mu g / L)$} \\
\hline & & $\begin{array}{c}\text { Before } \\
\text { treatment }\end{array}$ & $\begin{array}{c}\text { After } \\
\text { treatment }\end{array}$ & $\begin{array}{c}\text { Before } \\
\text { treatment }\end{array}$ & $\begin{array}{c}\text { After } \\
\text { treatment }\end{array}$ & $\begin{array}{c}\text { Before } \\
\text { treatment }\end{array}$ & $\begin{array}{c}\text { After } \\
\text { treatment }\end{array}$ \\
\hline Control group & 46 & $\begin{array}{c}235.08 \pm \\
10.22\end{array}$ & $45.98 \pm 3.15$ & $14.59 \pm 1.34$ & $10.38 \pm 1.01$ & $13.57 \pm 1.78$ & $\begin{array}{c}10.72 \pm \\
1.07\end{array}$ \\
\hline Observation group & 46 & $\begin{array}{c}236.12 \pm \\
11.01\end{array}$ & $38.12 \pm 5.76$ & $14.61 \pm 1.31$ & $8.95 \pm 1.14$ & $13.60 \pm 1.81$ & $8.61 \pm 1.02$ \\
\hline $\mathrm{t}$ & & 0.470 & 8.120 & 0.072 & 6.368 & 0.080 & 9.681 \\
\hline$p$ & & 0.640 & 0.000 & 0.943 & 0.000 & 0.936 & 0.000 \\
\hline
\end{tabular}


Xianhui Su et al.

Table-III: Comparison of peripheral blood immunity indexes between the two groups before and after treatment $(\bar{X} \pm \mathrm{s})$.

\begin{tabular}{lccccccc}
\hline & & \multicolumn{2}{c}{$C D 3^{+} C D 4^{+}$} & \multicolumn{2}{c}{$\mathrm{CD}^{+} \mathrm{CD} 56^{+}$} & \multicolumn{2}{c}{$\mathrm{CD3}^{+} \mathrm{CD} 4^{+} / \mathrm{CD}^{+} \mathrm{CD} 8^{+}$} \\
\cline { 3 - 8 } Group & Cases & $\begin{array}{c}\text { Before } \\
\text { treatment }\end{array}$ & $\begin{array}{c}\text { After } \\
\text { treatment }\end{array}$ & $\begin{array}{c}\text { Before } \\
\text { treatment }\end{array}$ & $\begin{array}{c}\text { After } \\
\text { treatment }\end{array}$ & $\begin{array}{c}\text { Before } \\
\text { treatment }\end{array}$ & $\begin{array}{c}\text { After } \\
\text { treatment }\end{array}$ \\
\hline Control group & 46 & $29.23 \pm 3.19$ & $35.12 \pm 3.16$ & $6.05 \pm 1.03$ & $6.98 \pm 1.06$ & $1.05 \pm 0.04$ & $1.53 \pm 0.05$ \\
Observation group & 46 & $29.25 \pm 3.22$ & $45.01 \pm 3.09$ & $6.04 \pm 1.09$ & $8.01 \pm 1.07$ & $1.06 \pm 0.03$ & $2.19 \pm 0.12$ \\
$\mathrm{t}$ & & 0.030 & 15.177 & 0.045 & 4.638 & 1.356 & 34.433 \\
$\mathrm{p}$ & & 0.976 & 0.000 & 0.964 & 0.000 & 0.178 & 0.000 \\
\hline
\end{tabular}

$(p<0.05)$ (Table-I).Before treatment, there was no significant difference in HE4, DJ-1 and HK-10 between the two groups $(p>0.05)$; after treatment, the indexes of HE4, DJ-1 and HK-10 in the two groups were significantly decreased, and the indexes of HE4, DJ-1 and HK-10 in the observation group were significantly lower than those in the control group $(p<0.05)$ (Table-II).

Before treatment, there was no significant differencein $\mathrm{CD}_{3}{ }^{+} \mathrm{CD}^{+}, \mathrm{CD}^{+}{ }^{+} \mathrm{CD} 56^{+}$and $\mathrm{CD} 3^{+} \mathrm{CD}^{+} /$ $\mathrm{CD}^{+}{ }^{+} \mathrm{CD} 8^{+}$between the two groups $(p>0.05)$; after treatment, the indexes of $\mathrm{CD} 3^{+} \mathrm{CD} 4^{+}, \mathrm{CD}^{+} \mathrm{CD} 56^{+}$ and $\mathrm{CD}^{+}{ }^{+} \mathrm{CD}^{+} / \mathrm{CD}^{+}{ }^{+} \mathrm{CD} 8^{+}$in the two groups were significantly increased, and the observation group had significantly higher indexes of $\mathrm{CD}^{+} \mathrm{CD}^{+}$,
$\mathrm{CD}^{+} \mathrm{CD}^{2} 6^{+}$and $\mathrm{CD}^{+} \mathrm{CD} 4^{+} / \mathrm{CD}^{+} \mathrm{CD}^{+}$when compared with the control group $(p<0.05)$ (TableIII).The severity of myelosuppression and nausea and vomiting in the observation group was significantly lower than that in the control group $(p<0.05)($ Table-IV).The total tumor metastasis rate of the observation group was significantly lower than that of the control group $(p<0.05)($ Table-V).

\section{DISCUSSION}

The fact of no obvious early clinical symptoms and the lack of clinical indicators with high sensitivity and specificity were suggested as the main reasons for the low rate of early diagnosis of $\mathrm{OC}$ in relevant patients, thus delaying the best

Table-IV: Comparison of adverse reactions between the two groups after treatment (n, \%).

\begin{tabular}{lccccc}
\hline Adverse reactions & Staging & Control group $(n=46)$ & Observation group $(n=46)$ & $Z$ & $p$ \\
\hline \multirow{4}{*}{ Myelosuppression } & 0 & $5(10.87)$ & $15(32.61)$ & & \\
& I & $6(13.04)$ & $20(43.48)$ & & \\
& II & $19(41.30)$ & $8(17.39)$ & 22.529 & 0.000 \\
& III & $12(26.09)$ & $3(6.52)$ & & \\
& IV & $4(8.70)$ & $0(0.00)$ & & \\
& 0 & $1(2.17)$ & $7(15.22)$ & & \\
Nausea and vomiting & I & $7(15.22)$ & $27(58.70)$ & & \\
& II & $20(43.48)$ & $9(19.57)$ & 28.959 & 0.000 \\
& III & $13(28.26)$ & $2(4.35)$ & & \\
\hline
\end{tabular}

Table-V: Comparison of tumor metastasis status between two groups after treatment (n, \%).

\begin{tabular}{lcccccc}
\hline Group & Cases & $\begin{array}{c}\text { Hepatic } \\
\text { metastases }\end{array}$ & $\begin{array}{c}\text { Peritoneal } \\
\text { metastasis }\end{array}$ & $\begin{array}{c}\text { Pulmonary } \\
\text { metastasis }\end{array}$ & $\begin{array}{c}\text { Metastasis to } \\
\text { other tissues }\end{array}$ & $\begin{array}{c}\text { Total metastasis } \\
\text { rate }\end{array}$ \\
\hline Control group & 46 & 4 & 4 & 5 & 3 & $16(34.78)$ \\
Observation group & 46 & 1 & 2 & 2 & 2 & $7(15.22)$ \\
$X^{2}$ & & & & & & 4.696 \\
$p$ & & & & & & 0.030 \\
\hline
\end{tabular}


treatment timing and increasing the physiological pain, economic burden and life risk of patients. ${ }^{13} \mathrm{At}$ present, the relevant academic world have not fully elucidated the cause of $\mathrm{OC}$, and the existing disease data showed that there was a high correlation between genetic factors and epithelial OC. In addition, it has been demonstrated that continuous ovulation and environment may also be high-risk pathological factors of OC. ${ }^{14}$ Generally, patients with malignant tumors of ovary would receive comprehensive treatment plans, that is, surgery combined with chemotherapy were applied to eliminate the lesion cells and prolong the survival of patients. ${ }^{15}$ For patients with advanced recurrent epithelial OC, cytoreductive surgery was more likely to be chosen, followed by chemotherapy with the combination of carboplatin, paclitaxel and other drugs. Different chemotherapy methods showed certain differences in the physiological recovery of patients. ${ }^{16}$ In order to explore a more efficient chemotherapy protocol, the physiological indexes of patients with advanced recurrent epithelial OC were compared and analyzed through performing intravenous chemotherapy and IPCH by grouping.

The results of our study showed that the response rate of the observation group was significantly higher than that of the control group, while the total tumor metastasis rate of the observation group was significantly lower than that of the control group, indicating that carboplatin combined with paclitaxel IPCH was more helpful to control the disease progression of advanced recurrent epithelial OC and reduce the risk of metastasis; and a previous study of Kuittinen et al. ${ }^{17}$ also supported our results. Wherein the pharmacological action of carboplatin was to destroy the normal components of DNA molecules and force the double coiled spiral structure to disintegrate, thus playing a role in inhibiting the proliferation of tumor cells. ${ }^{18}$

Paclitaxel could improve the secretion level of cytoplasmic microtubule dimer in the body and block the mitotic process of tumor cells. Moreover, it has been reported that carboplatin combined with paclitaxel could enhance the inhibitory effect on tumor cells. ${ }^{19} \mathrm{IPCH}$, a combination of hyperthermia and local chemotherapy, could not only improve the sensitivity of chemotherapy drugs to tumor cells and reduce the risk of metastasis and recurrence of tumor cells, but also further increase the drug content in the liver tissue and reduce the risk of liver metastasis because the administration site was in the abdominal cavity with shorter distance to inferior vena cava and hepatic portal vein.
Compared with intravenous chemotherapy, IPCH could ensure the utilization rate of chemotherapy drugs in the lesion site to a greater extent and improve the drug efficacy. ${ }^{20,21}$

Comparative analysis on the serum tumor markers of patients were carried out, and the results showed that, after treatment, the indexes of HE4, DJ-1 and HK-10 in the two groups decreased significantly, suggesting that the two chemotherapy methods may be helpful in the treatment of patients with advanced recurrent epithelial OC. However, the indexes of HE4, DJ-1 and HK-10 in the observation group were significantly lower than those in the control group, revealing that carboplatin combined with paclitaxel IPCH could improve the elimination rate of tumor cells. Furthermore, decreased secretion levels of serum tumor markers were observed in patients. HE4 could reflect ovarian cancer more sensitively, and had certain reference value in the diagnosis and prognosis evaluation of related diseases. In addition, abnormally increased concentration of HE4 in the body indicated that there was increased risk of tumor-associated diseases.

Riggs et al. ${ }^{21}$ also pointed out that HE4 was positively correlated with age, and the concentration of HE4 was continuously increased with age. DJ-1, a member of the peptidase C56 protein family, could prevent neurons from oxidative stress and death. At the same time, as a specific protein expressed in epithelial OC cells, DJ-1 could more sensitively reflect the proliferation status of tumor-related cells, thus providing an evaluation basis with reference value for evaluate the therapeutic effect in OC patients. ${ }^{22,23}$ As reported by a previous study, there was a positive correlation between HK-10 and the progression of OC cells, namely, the more serious the progression of OC cells, the higher the concentration of HK-10 in the body. ${ }^{24}$

In addition, our study also found that the indexes of $\mathrm{CD} 3+\mathrm{CD} 4+, \mathrm{CD} 3+\mathrm{CD} 56+$ and $\mathrm{CD} 3+\mathrm{CD} 4+$ / $\mathrm{CD} 3+\mathrm{CD} 8+$ in the two groups were significantly increased, indicating that the immune cell activity of patients was constantly improved, which was related to the decrease of malignant tumor cells, thus confirming the effectiveness of the two treatment plans. However, the indexes of $\mathrm{CD} 3+\mathrm{CD} 4+$, $\mathrm{CD} 3+\mathrm{CD} 56+$ and $\mathrm{CD} 3+\mathrm{CD} 4+/ \mathrm{CD} 3+\mathrm{CD} 8+$ in the observation group were significantly higher than those in the control group, further proving that the efficacy of carboplatin combined with paclitaxel IPCH was more significant.These findings were partly consistent with the conclusion of a related study. ${ }^{25}$ The chemotherapy drugs had certain 
cytotoxicity, after analyzing the adverse reactions of the two groups, the results showed that the severity of myelosuppression and nausea and vomiting in the observation group was significantly lower than that in the control group, demonstrating that IPCH could reduce the cytotoxicity of chemotherapy drugs and reduce the incidence of side effects, so that the safety was more guaranteed.

Limitations of the study More data may be obtained by stratified design according to body mass index; the study had a small sample size, short follow-up period and no more detailed subgroup comparison. Our findings were still needed to be further confirmed by more in-depth studies in the future.

\section{CONCLUSION}

For patients with advanced recurrent OC, carboplatin combined with paclitaxel IPCH could significantly reduce the secretion levels of serum tumor markers such as HE4 and DJ-1, enhance the therapeutic effect and reduce the risk of metastasis and the incidence of side effects, with a better clinical application prospect.

\section{Declaration of conflicting interest: None.}

Funding: None.

\section{REFERENCES}

1. Torre LA, Trabert B, DeSantis CE, Miller KD, Samimi G, Runowicz CD, et al. Ovarian cancer statistics, 2018. CA Cancer J Clin. 2018;68(4):284-296 doi: 10.3322/caac. 21456

2. Menon U, Karpinskyj C, Gentry-Maharaj A. Ovarian Cancer Prevention and Screening. Obstet Gynecol. 2018;131(5):909-927. doi: 10.1097/ AOG.0000000000002580

3. Orr B, Edwards RP. Diagnosis and Treatment of Ovarian Cancer. Hematol Oncol Clin North Am. 2018;32(6):943-964. doi: 10.1016/j.hoc.2018.07.010

4. Sehouli J, Grabowski JP. Surgery in recurrent ovarian cancer. Cancer. 2019;125(Suppl- 24):4598-4601. doi: 10.1002/cncr.32511

5. Keyvani V, Farshchian M, Esmaeili SA, Yari H, Moghbeli M, Nezhad SK, et al. Ovarian cancer stem cells and targeted therapy. J Ovarian Res. 2019;12(1):120. doi: 10.1186/s13048-019-0588-z

6. Baci D, Bosi A, Gallazzi M, Rizzi M, Noonan DM, Poggi A, et al. The Ovarian Cancer Tumor Immune Microenvironment (TIME) as Target for Therapy: A Focus on Innate Immunity Cells as Therapeutic Effectors. Int J Mol Sci. 2020;21(9):3125. doi: 10.3390/ijms21093125

7. Emmings E, Mullany S, Chang Z, Landen CN Jr, Linder S, Bazzaro M Targeting Mitochondria for Treatment of Chemoresistant Ovarian Cancer. Int J Mol Sci. 2019;20(1):229. doi: 10.3390/ijms20010229

8. Buechel M, Herzog TJ, Westin SN, Coleman RL, Monk BJ, Moore KN. Treatment of patients with recurrent epithelial ovarian cancer for whom platinum is still an option. Ann Oncol. 2019;30(5):721-732. doi: 10.1093/ annonc/mdz104

9. Chambers LM, Costales AB, Crean-Tate K, Kuznicki M, Morton M Horowitz $\mathrm{M}$, et al. A guide to establishing a hyperthermic intraperitoneal chemotherapy program in gynecologic oncology. Gynecol Oncol 2020;158(3):794-802. doi: 10.1016/j.ygyno.2020.06.487

10. Colombo N, Sessa C, du Bois A, Ledermann J, McCluggage WG, McNeish I, et al. ESMO-ESGO consensus conference recommendations on ovarian cancer: pathology and molecular biology, early and advanced stages, borderline tumours and recurrent disease. Ann Oncol. 2019;30(5):672-705. doi: $10.1093 /$ annonc/mdz062

11. Hodi FS, Ballinger M, Lyons B, Soria JC, Nishino M, Tabernero J, et al Immune-Modified Response Evaluation Criteria In Solid Tumors (imRECIST): Refining Guidelines to Assess the Clinical Benefit of Cancer Immunotherapy. J Clin Oncol. 2018;36(9):850-858. doi: 10.1200/JCO.2017.75.1644
12. Mao MH, Zhang J, Zhang JG. Comparing the RTOG/EORTC and LENT-SOMA scoring systems for the evaluation of late skin toxicity after 125I seed brachytherapy for parotid gland cancer. Brachytherapy. 2018;17(1):250. doi: 10.1016/j.brachy.2017.11.017

13. Stewart C, Ralyea C, Lockwood S. Ovarian Cancer: An Integrated Review Semin Oncol Nurs. 2019;35(2):151-156. doi: 10.1016/j.soncn.2019.02.001

14. Gupta KK, Gupta VK, Naumann RW. Ovarian cancer: screening and future directions. Int J Gynecol Cancer. 2019;29(1):195-200. doi: 10.1136/ijgc2018-000016

15. Nishio S, Ushijima K. Clinical significance of primary debulking surgery and neoadjuvant chemotherapy-interval debulking surgery in advanced ovarian cancer. Jpn J Clin Oncol. 2020;50(4):379-386. doi: 10.1093/jjco/ hyaa015

16. Vergote I, Scambia G, O'Malley DM, Van Calster B, Park SY, Del Campo JM, et al. Trebananib or placebo plus carboplatin and paclitaxel as firstline treatment for advanced ovarian cancer (TRINOVA-3/ENGOT-ov2/ GOG-3001): a randomised, double-blind, phase 3 trial. Lancet Oncol. 2019;20(6):862-876. doi: 10.1016/S1470-2045(19)30178-0

17. Kuittinen T, Rovio P, Luukkaala T, Laurila M, Grenman S, Kallioniemi A, et al. Paclitaxel, Carboplatin and 1,25-D3 Inhibit Proliferation of Ovarian Cancer Cells In Vitro. Anticancer Res. 2020;40(6):3129-3138. doi: 10.21873/ anticanres.14294

18. Mukherjee A, Chiang CY, Daifotis HA, Nieman KM, Fahrmann JF, Lastra RR, et al. Adipocyte-Induced FABP4 Expression in Ovarian Cancer Cells Promotes Metastasis and Mediates Carboplatin Resistance. Cancer Res. 2020;80(8):1748-1761. doi: 10.1158/0008-5472.CAN-19-1999

19. Lau TS, Chan LKY, Man GCW, Wong CH, Lee JHS, Yim SF, et al. Paclitaxel Induces Immunogenic Cell Death in Ovarian Cancer via TLR4/IKK2/ SNARE-Dependent Exocytosis. Cancer Immunol Res. 2020;8(8):1099-1111. doi: 10.1158/2326-6066.CIR-19-0616

20. van Driel WJ, Koole SN, Sikorska K, Schagen van Leeuwen JH, Schreuder HWR, Hermans RHM, et al. Hyperthermic Intraperitoneal Chemotherapy in Ovarian Cancer. N Engl J Med. 2018;378(3):230-240. doi: 10.1056/NEJMoa1708618

21. Riggs MJ, Pandalai PK, Kim J, Dietrich CS. Hyperthermic Intraperitoneal Chemotherapy in Ovarian Cancer. Diagnostics (Basel). 2020;10(1):43. doi: 10.3390/diagnostics10010043

22. Dochez V, Caillon H, Vaucel E, Dimet J, Winer N, Ducarme G. Biomark ers and algorithms for diagnosis of ovarian cancer: CA125, HE4, RMI and ROMA, a review. J Ovarian Res. 2019;12(1):28. doi:10.1186/s13048-019-0503-7

23. Schumann C, Chan S, Millar JA, Bortnyak Y, Carey K, Fedchyk A, et al. Intraperitoneal nanotherapy for metastatic ovarian cancer based on siRNAmediated suppression of DJ-1 protein combined with a low dose of cisplatin. Nanomedicine. 2018;14(4):1395-1405. doi: 10.1016/j.nano.2018.03.005

24. Yu C, Dou T, Liu Y, Liu R. Clinical value of TV-CDS combined with serum tumor markers in diagnosis of ovarian cancer. Oncol Lett. 2020;20(2):20282034. doi: $10.3892 / o l .2020 .11705$

25. De La Motte Rouge T, Corne J, Cauchois A, Le Boulch M, Poupon C Henno S, et al. Serum CD95L Level Correlates with Tumor Immune Infiltration and is a Positive Prognostic Marker for Advanced High-Grade Serous Ovarian Cancer. Mol Cancer Res. 2019;17(12):2537-2548. doi: 10.1158/1541-7786.MCR-19-0449

\section{Authors' Contributions:}

XS and XS designed this study and prepared this manuscript,and are responsible and accountable for the accuracy or integrity of the work.

YD collected and analyzed clinical data.

YK significantly revised this manuscript.

Authors:

1. Xianhui Su,

Department of Pharmacology,

2. Xuewen Sun,

Department of Pathogenic Biology,

3. Yanhui Kang,

Department of Pharmacology,

4. Yuna Dai,

Department of Breast Surgery,

Affiliated Hospital of Hebei Engineering University,

Handan 056029,

Hebei,China.

1-3: Medical College of Hebei Engineering University,

Handan, 056038,

Hebei, China. 